\title{
Intercellular communication, NO and the biology of Chinese medicine
} Dina Ralt*

Address: Izun \& Tmura, Integrative Health Inst. 6 Nezach Israel st. Tel Aviv, Israel 64352

Email: Dina Ralt* - Izun.Tmura@gmail.com

* Corresponding author

Published: 18 May 2005

Cell Communication and Signaling 2005, 3:8 doi:10.1 I86/1478-8IIX-3-8

This article is available from: http://www.biosignaling.com/content/3/l/8

(c) 2005 Ralt; licensee BioMed Central Ltd.

This is an Open Access article distributed under the terms of the Creative Commons Attribution License (http://creativecommons.org/licenses/by/2.0), which permits unrestricted use, distribution, and reproduction in any medium, provided the original work is properly cited.
Received: 02 April 2005

Accepted: 18 May 2005

\begin{abstract}
New multiple categories of health disciplines have become popular in the west and integration between the medicinal approaches has become essential.

The hypothesis presented here suggests a novel integrative view that combines Western biochemistry with the Chinese medicinal concept of qi.

The core for this hypothesis is that transmission of qi along the meridians is based on informational molecules that travel via an intercellular communication system. Acupuncture at specific points enhances the flow of the signaling molecules through this communication system.

Nitric oxide is suggested as a prime candidate for such a signaling molecule in the meridian system. The biochemistry of nitric oxide can shed light on the biology underlying Chinese medicine while Chinese medicinal data can provide a clue to the sought after framework for nitric oxide.
\end{abstract}

\section{Introduction}

Recently there has been a great fervor in the health field around the inclusions of non-traditional disciplines [1]. For example, eastern medicines, naturopathy and healing have become popular and were recently introduced into medical school curricula. These changes have made Chinese medicine $[2,3]$ attainable in the west just as Western medicine is to the east. However, open-mindedness [4,5] or legality $[6,7]$ does not necessarily imply true integration between the medicinal approaches.

The aim of this article is to suggest a novel integrative view of the key concept in Chinese medicine, qi, meridians and acupuncture, with Western biochemistry. The crux of the hypothesis is that the transmission of qi along the meridians, involves informational molecules, which travel via an intercellular communication system, and, acupuncture at specific points enhances this communication system.

Nitric oxide (NO) is proposed here as a prime candidate for such a signaling molecule in the meridian system.

One analogy that can be made is to consider the word HELLO as an example to the signaling molecule. The information that HELLO transfers is not only the meaning of the word, which is HI, but mainly the way by which it is expressed e.g., loud, smiling, sad, laughing. If we think of NO in the context of a word like HELLO, it is suggested that the meaning of qi is not only a word like HI but rather an abundance of bodily information. 


\section{Discussion Nitric Oxide}

NO has been the most widely studied signaling molecule for more than a decade. It regulates blood pressure, contributes to the immune responses, controls neurotransmission and participates in cell differentiation and in many more physiological functions [8].

Nitric oxide (NO) the diffusible, signaling gas, is synthesized by 3 nitric oxide synthase isoforms (NOS): a neuronal (nNOS), inducible (iNOS) [9], or endothelial NO synthetase (eNOS) $[10,11]$. Using BH4 (tetrahydrobiopterin) [12] as a cofactor, these enzymes convert arginine to citruline and NO. The levels of NOS are altered by a variety of pathophysiological conditions such as hypertension, hypercholesterolemia, aging, cigarette smoking, diabetes, heart failure and under physical activity [13] and dementia [14].

NOS were also shown to be associated with a plethora of more than 20 proteins that affect the activity and spatial organization of NO synthesis within the cell. Some of these interactions may have functions beyond NO formation [15].

NO is such a crucial entity that the mammalian genome encodes three NOS genes with partially overlapping function that may compensate for each other if one of them is not functioning. For example, the essentiality and flexibility of the NO system allows nNOS enzyme to compensate for eNOS, in mutant mice lacking eNOS $[16,17]$. Recently NOS was shown to be essential for development (in Drosophila) by taking advantage of the fact that, unlike those of mammals, the genome of the fruit fly has only one NOS gene and is thus more amenable to mutagenesis [18].

\section{Qi, meridians and acupuncture}

The idea of qi is fundamental to Chinese medical thinking. Qi is involved with all biological functions and circulates throughout meridians reaching the entire human body $[19,20]$. The goal of acupuncture as well as other Eastern medicinal methods (herbs, massage, Qigong) is to ensure the unobstructed flow of qi. When qi is strengthened or balanced, it can improve health and ward off or slow the progression of disease. Chinese medicine considers sickness or pain, a result of the qi blockage or unbalanced qi energy in the body [2]. Like NO, qi is essential for life, as Guanzi said [21] in $5^{\text {th }}$ century BCE, "When there is qi, there is life".

Much information has accumulated regarding the physiological effects of acupuncture. In 1998, a NIH panel concluded that acupuncture is an effective technique for relieving nausea and vomiting and an effective agent for relieving pain [22]. Needling of acupuncture points has subjective (needle sensation) and objective (e.g., serum cortisol increase or $\mathrm{Ca}(2+)$ oscillations) effects $[23,24]$. Acupuncture increases blood flow [25] and acupuncture points have high electrical conductance $[26,27]$. A relationship between acupuncture points and meridians to connective tissue planes [28] and perivascular space [29] has also been suggested. Possible mechanisms of acupuncture have been reviewed [30] and data are available at the site of the National Center for Complementary and Alternative medicine [NCCAM] [31]. They include conduction of electromagnetic signals, activation of opioid systems or changes in brain chemistry, sensation and involuntary body functions.

This article does not deal with the physiological effects of qi manipulation but rather with the nature of qi flow along the meridians. The hypothesis is that the transmission of qi is based on an intercellular communication system and that nitric oxide (NO) is a prime candidate to be a signaling molecule in the meridian system.

\section{Information and signals}

Information links increase the ability to handle complexity and thus, control mechanisms in the body can be regarded as information processing. This was proposed by H. R. Maturana \& F. Varela in the concept of Autopoiesis, the process by which systems organize themselves out of disorder, forming a responsive, self-maintaining network characteristic of life [32]. Autopoiesis is parallel to the concept of qi, streaming along the meridians' net, regulating our well being.

It is expected that the qi type signal molecule in the body, will be an essential entity and probably a gas so that it can spread as well as dissipate very quickly to allow following information to be transferred. Furthermore, the dual nature of NO $[33,34]$, being either beneficial or detrimental, is parallel to the dual nature of qi [19] and fits the basic character of a signal. Signals can not always be beneficial, in that "cost" must be associated with them to ensure their "integrity", e.g., those who wish to transmit information about their richness, are likely to exhibit it by expensive jewels or costly cars, signals which are hazardous to poor people who can't afford them $[35,36]$. With biochemical signals, such integrity can be attained by variety of costly characters, see for example cAMP and Ca2+ [37] or Glutamate and GABA [38]. One of such characters may be the toxicity of a molecule like $\mathrm{NO}$ which demands very cautious and strict handling. NO differs from other neurotransmitters in that its levels are regulated solely by synthesis, rather than by storage, release or targeted degradation. NO is impossible to live without, short lived, highly diffusible and toxic [39] and is thus an excellent 
candidate for a cellular communication signal which carries the qi information.

\section{Conclusion}

What is known and what needs to be studied

The proposal presented here of NO as the carrier of qi along the meridians already has initial scientific support. Data are being accumulated indicating the tight relations between NO and acupoint manipulation. First, in rats, NO has been shown to play a role in mediating the cardiovascular responses to electroacupuncture at point 36ST $[40,41]$, Second, acupuncture was shown to modulate the expression of NOS under diabetic conditions $[42,43]$. Additional experiments demonstrated that acupuncture increased the level of iNOS mRNA in macrophages [44] and while examining the distributions of $\mathrm{NO}$ in the skin points of rats it was shown that NO contents and nNOS expression were consistently higher in the skin acupoints/ meridians associated with low electric resistance [45]. Together these data show that NO is associated with the functions of acupoint/meridian including their low electric resistance.

An initial human clinical study was performed in China and showed that the NO contents of peripheral blood increased significantly after acupuncture/moxibustion at point 36ST [46].

It is important to note that because $\mathrm{NO}$ is involved in multiple body functions, its presence in the peripheral blood or in an acupuncture point is a supportive but not a sufficient proof for the hypothesis.

In general a necessary approach in this case is to incorporate into the NO measures the interrelations of the meridian points based on the Chinese medicine principles $[19,47]$. Manipulating a distant point on the meridian and measure NO in another part of the body, or blocking $\mathrm{NO}$ in one part of the body and measure inhibition of a distant meridian manipulation, will demonstrate the meridian net via the NO biochemistry and the essentiality of NO in the control mechanisms of Chinese medicine.

\section{Final words}

Traditional Chinese medicine, which was created over 2500 years ago, can play the key role in the formation of a novel integrative medicine. It can be characterized as holistic with an emphasis on the integrity of the human body and its close relationship with the environment. It is interesting to note that ancient mummies (stone aged) were discovered in Europe and in Peru, these mummies have tattoo lines partly overlapping meridians [48], so it seems that not only the Chinese have noticed this biological net.
The elucidation of the molecular basis of qi will open a vast opportunity to integrate the Chinese medical philosophy with current biological research on cellular communication, as well as with information technology in general, a theme which has become one of the main issues of our time $[49,50]$. Moreover, If NO is indeed a qi transmitter, the Chinese knowledge can be used as a clue to the sought after framework for NO [8] in Western medicine and further establish the link between Chinese and Western medicines. Are meridians the generic net of life? Are the major acupoints it's hubs? [51].

\section{References}

I. Snyderman R, Weil AT: Integrative medicine: bringing medicine back to its roots. Arch Intern Med 2002, I 62:395-397.

2. Zhu-Fan X, et al.: Acupuncture: WHO Review and analysis of reports on controlled clinical trials 2002 [http://www.who.int/medicines/library/ trm/acupuncture/clinicreportsacupuncture.shtml]. ISBN 924 I54543 7, WHO Geneva

3. Lu AP, Jia HW, Xiao C, Lu QP: Theory of traditional Chinese medicine and therapeutic method of diseases. World J Gastroenterol 2004, 10:1854-1856.

4. Nestler G: Traditional Chinese medicine. Med Clin North Am 2002, 86:63-73.

5. Shang C: The future of integrative medicine. Arch Intern Med 200I, I6I:6I3-6I4.

6. Sidley P: South Africa to regulate healers. BMJ 2004, 329:758.

7. White C: Regulatory body proposed for acupuncturists and herbalists. BM/ 2004, 328:604.

8. Greener M: Now You're Signaling, With Gas. The Scientist 2004, I 8:17 [http://www.the-scientist.com/yr2004/sep/ research $040913 . \mathrm{html}$.

9. Lowenstein CJ, Padalko E: iNOS (NOS2) at a glance. J Cell Sci 2004, I I 7:2865-2867.

10. Alderton WK, Cooper CE, Knowles RG: Nitric oxide synthases: structure, function and inhibition. Biochem J 200I, 357:593-6I5.

II. Li H, Wallerath T, Forstermann U: Physiological mechanisms regulating the expression of endothelial-type NO synthase. Nitric Oxide 2002, 7: I32-147

12. Werner ER, Gorren AC, Heller R, Werner-Felmayer G, Mayer B: Tetrahydrobiopterin and nitric oxide: mechanistic and pharmacological aspects. Exp Biol Med (Maywood) 2003, 228: $|29|-\mid 302$.

13. Harrison DG: Cellular and Molecular Mechanisms of Endothelial Cell Dysfunction. J Clin Invest 1997, I 00:2 I53-2I 57.

14. Law A, Gauthier S, Quirion R: Say NO to Alzheimer's disease: the putative links between nitric oxide and dementia of the Alzheimer's type. Brain Research Reviews 200I, 35:73-96.

15. Nedvetsky PI, Sessa WC, Schmidt HH: There's NO binding like NOS binding: Protein-protein interactions in NO/cGMP signaling. Proc Natl Acad Sci USA 2002, 99: I65 I0-16512.

16. Heinrich UR, Lioudyno M, Maurer J, Mann W, Guth PS, Forstermann $U$ : Localization of the two constitutively expressed nitric oxide synthase isoforms (nNOS and eNOS) in the same cell types in the saccule maculae of the frog Rana pipiens by immunoelectron microscopy: evidence for a back-up system? J Electron Microsc (Tokyo) 2003, 52:197-206.

17. Sanz MJ, Hickey MJ, Johnston B, McCafferty DM, Raharjo E, Huang PL, Kubes P: Neuronal nitric oxide synthase (NOS) regulates leukocyte-endothelial cell interactions in endothelial NOS deficient mice. Br J Pharmacol 200I, I 34:305-3I2.

18. Regulski M, Stasiv Y, Tully T, Enikolopov G: Essential function of nitric oxide synthase in Drosophila. Curr Biol 2004, I 4:R881-R882.

19. Kaptchuk TJ: The Web That Has No Weaver: Understanding Chinese Medicine 1983 [http://www.amazon.com/gp/reader/0809228408/ ref=sib dp pt/102-844||86-2|52||4\#reader-link]. Congdon \& Weed, Inc. New York

20. Ralt D: Qi, Information and the Net of Life. Acupuncture in Medicine 1999, I 7:131-134 [http://www.medical-acupuncture.co.uk/jour nal/I999dec/I2.shtml]. 
21. Rickett WA: Guanzi: Political, Economic, and Philosophical Essays from Early China 1998 [http://pup.princeton.edu/titles/6331.html]. Princeton University Press

22. Acupuncture NIH Consensus Statement: 3-5 November $1997: 1-34$ [http://odp.od.nih.gov/consensus/cons/107//07 intro.htm].

23. Roth LU, Maret-Maric A, Adler RH, Neuenschwander BE: Acupuncture Points have Subjective and Objective Specificity. Acupuncture in Medicine 1997, 15:1 [http://www.medicalacupuncture.co.uk/journal/may 1997/one.shtml].

24. Deng QK: A new approach for exploring the essence of meridian. Di Yi Jun Yi Da Xue Xue Bao 2003, 23:409-4I 3.

25. Sandberg M, Lundeberg T, Lindberg LG, Gerdle B: Effects of acupuncture on skin and muscle blood flow in healthy subjects. Eur J Appl Physiol 2003, 90: I |4-I I9.

26. Shang C: Electrophysiology of growth control and acupuncture. Life Sci 2001, 68: I333-I342.

27. Johng HM, Cho JH, Shin HS, Soh KS, Koo TH, Choi SY, Koo HS, Park MS: Frequency dependence of impedances at the acupuncture point Quze (PC3). IEEE Eng Med Biol Mag 2002, 2 I:33-36.

28. Langevin HM, Yandow JA: Relationship of acupuncture points and meridians to connective tissue planes. Anat $\operatorname{Rec} 2002$, 269:257-265.

29. Ma W, Tong H, Xu W, Hu J, Liu N, Li H, Cao L: Perivascular space: possible anatomical substrate for the meridian. J Altern Complement Med 2003, 9:85I-859.

30. Ma SX: Neurobiology of Acupuncture: Toward CAM. Evid Based Complement Alternat Med 2004, I:41-47.

31. Acupuncture NCCAM Publication No. D003 2004 [http:// nccam.nih.gov/health/acupuncture/index.htm].

32. Rudrauf D, Lutz A, Cosmelli D, Lachaux JP, Le Van Quyen M: From autopoiesis to neurophenomenology: Francisco Varela's exploration of the biophysics of being. Biol Res 2003, 36:27-65.

33. Poon BY, Raharjo E, Patel KD, Tavener S, Kubes P: Complexity of inducible nitric oxide synthase: cellular source determines benefit versus toxicity. Circulation 2003, I08: | I07-I | I 2.

34. Hoit BD: Two Faces of Nitric Oxide, Lessons Learned From the NOS2 Knockout. Circulation Research 200I, 89:289.

35. Zahavi A: The fallacy of conventional signaling. Philos Trans $R$ Soc Lond B Biol Sci 1993, 340:227-230.

36. Donaths JS: Identity and Deception in the Virtual Community, Communities in Cyberspace 1998 [http://smg.media.mit.edu/people/]udith/Identity/ IdentityDeception.html]. London: Routledge

37. Bruce JI, Straub SV, Yule DI: Crosstalk between cAMP and Ca2+ signaling in non-excitable cells. Cell Calcium 2003, 34:43 I-44.

38. Lujan R, Shigemoto R, Lopez-Bendito G: Glutamate and GABA receptor signalling in the developing brain. Neuroscience 2005, I 30:567-80.

39. Marletta MA, Spiering MM: Trace elements and nitric oxide function. J Nutr 2003, I 33: I43 IS-I433S.

40. Chen S, Ma SX: Nitric Oxide in the Gracile Nucleus Mediates Depressor Response to Acupuncture (ST36). J Neurophysiol 2003, 90:780-785.

41. Ma SX, Ma J, Moise G, Li XY: Responses of neuronal nitric oxide synthase expression in the brainstem to electroacupuncture Zusanli (ST 36) in rats. Brain Res 2005, 1037:70-77.

42. Jang MH, Shin MC, Koo GS, Lee CY, Kim EH, Kim Cl: Acupuncture decreases nitric oxide synthase expression. Neurosci Lett 2003, 337: $155-158$.

43. Jang $\mathrm{MH}$, et al: Acupuncture increases nitric oxide synthase expression in hippocampus of streptozotocin-induced diabetic rats. Am J Chin Med 2003, 3 I:305-3I 3.

44. Zheng N, Wang Y, Wu J, Wang H, Ding Y: Acupuncture effects on inducible nitric oxide synthase mRNA, iNOS product and heat shock protein in peritoneal macrophages of the mouse. World J Acupuncture Moxibustion 1998, 8:35-38 [http://www.med boo.com/eng/wjam/].

45. Ma SX: Enhanced nitric oxide concentrations and expression of nitric oxide synthase in acupuncture points/meridians. J Altern Complement Med 2003, 9:207-2I5.

46. Li S, Chen K, Wu Y, Jiao J, Tao L: Effects of warm needling at zusanli (ST 36) on NO and IL-2 levels in the middle-aged and old people. J Tradit Chin Med 2003, 23:127-128.

47. Schnyer RN, Allen JJB: Acupuncture in the Treatment of Depression: $A$ Manual for Practice and Research 200I [http://www.heall.com/body/alt med/treatment/disease/psychological/depression/acupuncturehelps depression.html]. Churchill Livingstone, Harcourt Publishers Limited
48. Dorfer L, Moser M, Bahr F, Spindler K, Egarter-Vigl E, Giullen S, Dohr $\mathrm{G}$, Kenner T: A medical report from the stone age? Lancet 1999 , 354: $1023-1025$

49. Rao CV, Arkin AP: Control motifs for intracellular regulatory networks. Annu Rev Biomed Eng 200I, 3:39I-4I9.

50. Amaral LA, Díaz-Guilera A, Moreira AA, Goldberger AL, Lewis A, Lipsitz LA: Emergence of complex dynamics in a simple model of signaling networks. Proc Natl Acad Sci USA 2004, I0I:I555I-I5555.

5I. Xia Y, Yu H, Jansen R, Seringhaus M, Baxter S, Greenbaum D, Zhao $H$, Gerstein $M$ : Analyzing cellular biochemistry in terms of molecular networks. Annu Rev Biochem 2004 73: I 05 I - I087 [http:I /www.ncbi.nlm.nih.gov/entrez/ query.fcgi?cmd=Retrieve \&db=pubmed\&dopt=Abstract\&list uids $=\mid 5$ |89|67\&query $\mathrm{hl}=24]$
Publish with Biomed Central and every scientist can read your work free of charge

"BioMed Central will be the most significant development for disseminating the results of biomedical research in our lifetime. "

Sir Paul Nurse, Cancer Research UK

Your research papers will be:

- available free of charge to the entire biomedical community

- peer reviewed and published immediately upon acceptance

- cited in PubMed and archived on PubMed Central

- yours - you keep the copyright 